\title{
Analysis of Daily Global Solar Radiation Data for Wuhan
}

\author{
Zhengguo Gong, Yingni Jiang, Hao Yang and Jingbo Liu \\ The Logistic University Of PAPF, Tianjin 300300, China
}

\begin{abstract}
In order to improve knowledge on solar resources, this paper analyses the models correlating daily global solar radiation with sunshine duration for Wuhan, China. Estimated values were compared with measured values in terms of statistical error tests such as mean percentage error (MPE), mean bias error (MBE), root mean square error (RMSE). The model performing best was selected. The global solar radiation estimated from the best model was compared with measured values. It was determined that the predicted values have good agreement with the measured values at high daily global solar radiation.
\end{abstract}

\section{INTRODUCTION}

Solar radiation data are essential for both energy efficient building design and solar systems developments. Unfortunately, for many cases, solar radiation measurements are not easily available due to the cost and maintenance and calibration requirements of the measuring equipment. In order to achieve this, several empirical models have been developed to predict the solar radiation all over the world using various parameters. These parameters include extraterrestrial radiation, sunshine hours, mean temperature, maximum temperature, soil temperature, relative humidity, number of rainy days, altitude, latitude and cloudiness [1-10].

The most commonly used parameter for estimating global solar radiation in the publications is sunshine duration. Sunshine duration can be easily and reliably measured and data are widely available. The most widely used method is that of Angström [1], who proposed a linear relationship between the ratio of average daily global radiation to the corresponding value on a completely clear day and the ratio of average daily sunshine duration to the maximum possible sunshine duration.
The main objective of this paper is to estimate the daily global solar radiation with measured daily sunshine duration data from Wuhan, and to find the most suitable model for global radiation estimation at Wuhan, China.

\section{DATA USED AND METHODS OF COMPUTATION}

\subsection{Database}

Wuhan meteorological station is chosen for the case study. Wuhan $\left(30.6^{\circ} \mathrm{N}, 114.1^{\circ} \mathrm{E}\right)$ is located in the interior of China, at an altitude of $23.1 \mathrm{~m}$. A database containing daily measured global solar radiation and sunshine duration of Wuhan station was obtained from China Meteorological administration. In this paper ten years' recorded daily solar radiation from 1995 to 2004 are used.

\subsection{Methods of computation}

In the present work, the following correlations were used to express the dependence of global radiation on various parameters:

$$
\frac{H_{g}}{H_{0}}=a_{1}+a_{2} \frac{S}{S_{0}}
$$




$$
\frac{H_{g}}{H_{0}}=a_{3}+a_{4} \frac{S}{S_{0}}+a_{5}\left(\frac{S}{S_{0}}\right)^{2}
$$

$$
\frac{H_{g}}{H_{0}}=a_{6}+a_{7} \frac{S}{S_{0}}+a_{8}\left(\frac{S}{S_{0}}\right)^{2}+a_{9}\left(\frac{S}{S_{0}}\right)^{3}
$$

where $H_{g}$ is daily global solar radiation on a horizontal surface, $H_{0}$ is the daily value of the extraterrestrial radiation, $S$ is sunshine duration, $S_{0}$ is the maximum possible sunshine duration, $a$ are empirical coefficients.

The daily value of the extraterrestrial radiation on a horizontal surface was defined as [11]:

$$
H_{0}=\frac{24 \times 3600}{\pi} I_{0} f\left(\cos \lambda \cos \delta \sin \omega_{s}+\frac{\pi}{180} \omega_{s} \sin \lambda \sin o\right)
$$

where $I_{0}$ is the new solar constant $(=1367 \mathrm{~W} / \mathrm{m} 2$ [12]), $f$ is the eccentricity correction factor, $\lambda$ is the latitude of the site, $\delta$ the solar declination and $\omega_{s}$ the sunrise hour angle. The eccentricity correction factor, solar declination and sunrise hour angle can be respectively calculated as [11]:

$$
\begin{array}{r}
f=1+0.33\left(\cos \frac{360 n}{365}\right) \\
(5) \\
\delta=23.45 \sin \left[\frac{360(284+n)}{365}\right] \\
\omega_{s}=\arccos (-\tan \lambda \tan \delta)
\end{array}
$$

where $n$ is the number of day of year starting from first of January.
The maximum possible sunshine duration $\left({ }^{S_{0}}\right)$ can be obtained as [11]:

$$
S_{0}=\frac{2}{15} \omega_{s}
$$

Fig.1 presents the plot of $H_{g} / H_{0}$ against $S / S_{0}$ at Wuhan (1995-2004). It can be seen that the relationship between daily global solar radiation and daily sunshine duration is rather strong.

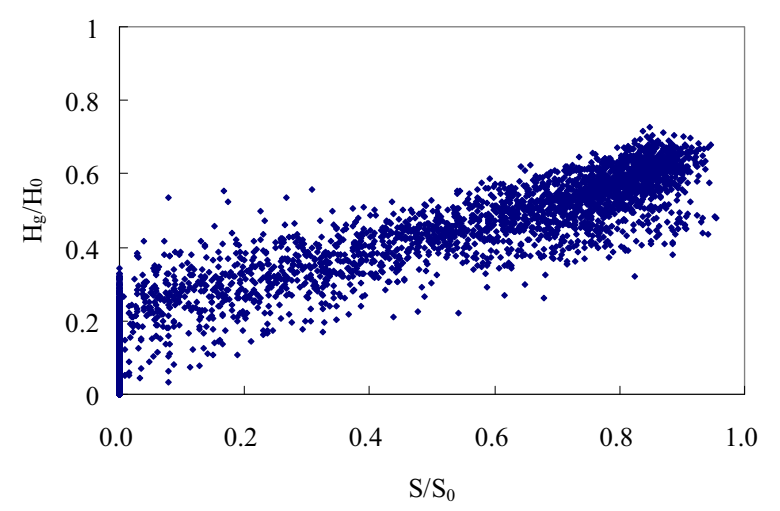

Fig.1. Relationship between $H_{g} / H_{0}$ and $S / S_{0}$ of Wuhan (1995-2004) obtained from the observed data

\subsection{Methods of comparison}

In this study, three statistical tests, mean percentage error (MPE), mean bias error (MBE) and root mean square error (RMSE) were used to estimate the accuracy of the correlations described above.

The mean percentage error is defined as:

$$
M P E=\frac{1}{N} \sum_{i=1}^{N}\left(\frac{D_{i e}-D_{i m}}{D_{i m}}\right) \times 100
$$

The mean bias error is defined as:

$$
M B E=\sum_{i=1}^{N}\left(D_{i e}-D_{i m}\right) / N
$$

The root mean square error is defined as:

$$
R M S E=\sqrt{\sum_{i=1}^{N}\left(D_{i e}-D_{i m}\right)^{2} / N}
$$


where $D_{i e}$ is the ith estimated value, $D_{i m}$ is the ith measured value and $N$ is the total number of observations.

The mean bias error test provides information on the long term performance. A low MBE is desired. A positive value gives the average amount of over estimation of an individual observation, which will cancel an under-estimation in a separate observation. The root mean square error RMSE gives information on the short term performance of the correlations by allowing a term by term comparison of the actual deviation between the calculated and measured values. The smaller the value, the better the model's performance is.

\section{Results and Discussion}

The obtained empirical coefficients of the Eqs.(1)-(3) are expressed as follows:

Model 1

$$
\frac{H_{g}}{H_{0}}=0.134+0.547 \frac{S}{S_{0}}
$$

\section{Model 2}

$\frac{H_{g}}{H_{0}}=0.120+0.786 \frac{S}{S_{0}}-0.292\left(\frac{S}{S_{0}}\right)^{2}$

\section{Model 3}

$\frac{H_{g}}{H_{0}}=0.112+1.240 \frac{S}{S_{0}}-1.741\left(\frac{S}{S_{0}}\right)^{2}+1.106\left(\frac{S}{S_{0}}\right)^{3}$ (14)

Table 1 shows MPE, MBE and RMSE errors for the three daily global radiation models (models (1-3) corresponding to Eqs.(12)-(14) respectively) of Wuhan station during the period 1995-2004. From this table, the MBE values obtained from models $(1,2,3)$ are all negative, which shows that these models under estimate global radiation. The RMSE value, which is a measure of the accuracy of estimation, has been found to be smallest for model $3(2.362 \mathrm{MJ} / \mathrm{m} 2)$, see Table 1. Also, MPE, MBE and RMSE are shown in Fig.1-3, respectively. As a result, model 3 performs better than the other models. The MPE,
MBE and RMSE of model 3 are $131.4 \%,-0.0041 \mathrm{MJ} / \mathrm{m} 2$ and $2.362 \mathrm{MJ} / \mathrm{m} 2$.

Table 1: Prediction errors for daily global solar radiation of three models

\begin{tabular}{lccc}
\hline & MPE $(\%)$ & MBE $\left(\mathrm{MJ} / \mathrm{m}^{2}\right)$ & RMSE $\left(\mathrm{MJ} / \mathrm{m}^{2}\right)$ \\
\hline Model 1 & 159.7 & -0.0219 & 2.511 \\
Model 2 & 141.6 & -0.0116 & 2.417 \\
Model 3 & 131.4 & -0.0041 & 2.362 \\
\hline
\end{tabular}

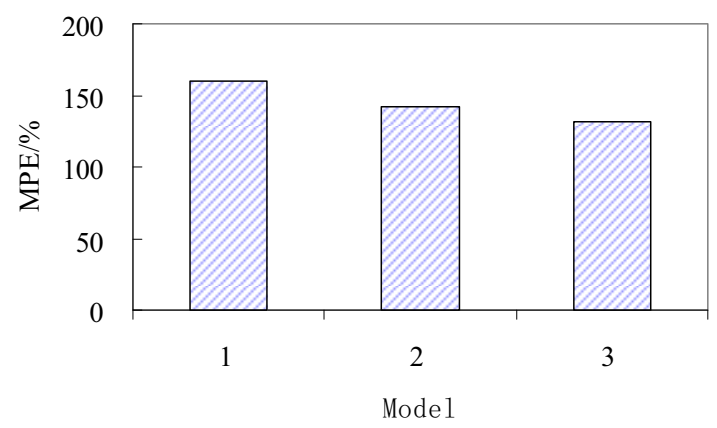

Fig.2. MPE of the three models

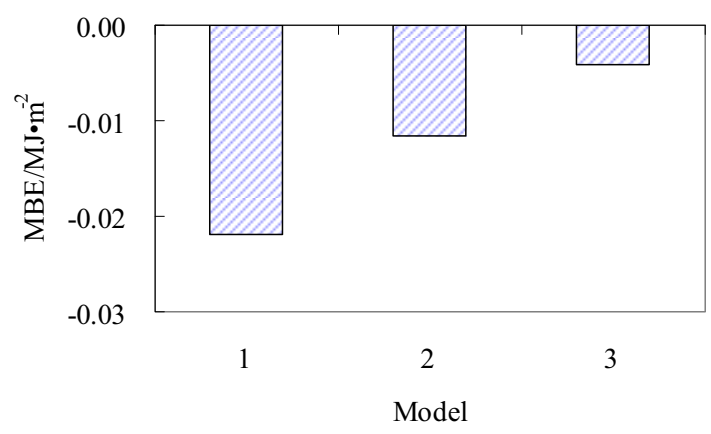

Fig.3. MBE of the three models

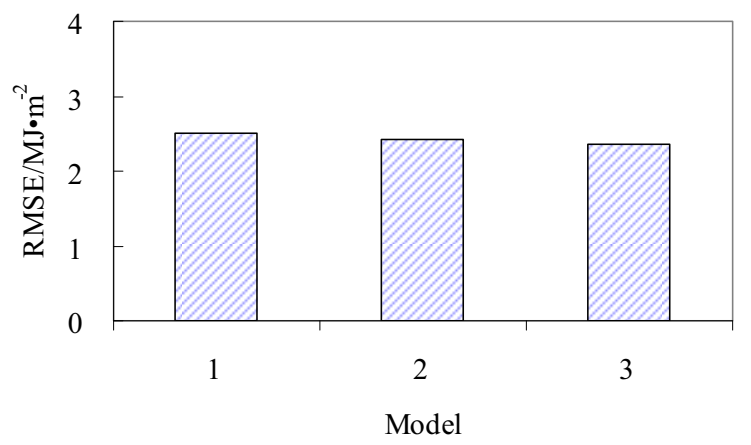

Fig.4. RMSE of the three models

To compare observed and estimated global radiation values of model 3 for Wuhan (1995-2004), Fig.5 is 
provided. Model 3 has large errors in estimating observed solar radiation at low daily global solar radiation. But it is of little consequence for solar energy operated systems, because low global radiation constitutes only a small part of the whole radiation. Fig. 5 suggests the good fitness between the observed and the estimated values when daily global solar radiation values are high.

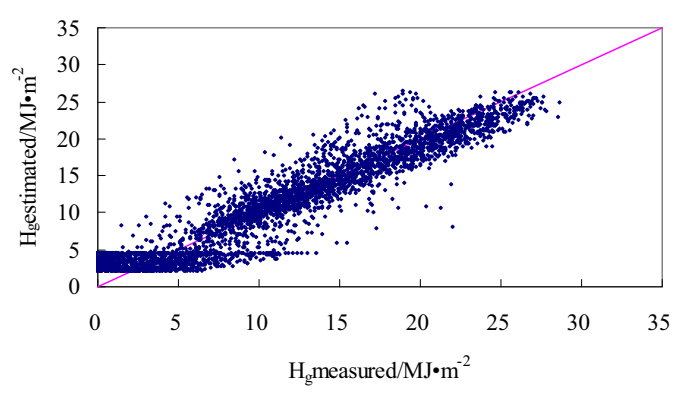

Fig.5. The measured and predicted ( by model 3 ) values of daily global solar radiation for Wuhan 1

\section{Conclusions}

This work demonstrated the efficient computation of daily global solar radiation from an estimation of $H_{g}$ vs. $S / S_{0}$ using data from Wuhan, China. The data set covers a period of 10 years (1995-2004). Linear, quadratic and cubic models were tried to estimate $H_{g}$ from $S / S_{0}$. It was found that $H_{g}$ can easily be estimated using the cubic model when the value of $H_{g}$ is large.

\section{References}

[1] Angström A. Solar and terrestrial radiation. Quarterly Journal of Royal Meteorological Society 1924; 50: 121-126.

[2] Tiba C. Analysis of monthly time series of solar radiation and sunshine hours in tropical climates. Renewable Energy 2004; 29(7): 1147-1160.

[3] Ehnberg JSG., Bollen MHJ. Simulation of global solar radiation based on cloud observations. Solar Energy 2005; 78(2):157-162.

[4] Skeiker K. Correlation of global solar radiation with common geographical and meteorological parameters for Damascus province, Syria. Energy Conversion and Management 2006; 47(4): 331-345.

[5] Forero NL, Caicedo LM, Gordillo G. Correlation of global solar radiation values estimated and measured on an inclined surface for clear days in Bogota. Renewable Energy 2007; 32(15): 2590-2602.

[6] Sabziparvar AA, Shetaee H. Estimation of global solar radiation in arid and semi-arid climates of East and West Iran. Energy 2007, 32(5):649-655.

[7] Bulut H, Büyükalaca O. Simple model for the generation of daily global solar-radiation data in Turkey. Applied Energy 2007; 84(5): 477-491.

[8] Sabziparvar AA. A simple formula for estimating global solar radiation in central arid deserts of Iran. Renewable Energy 2008; 33(5): 1002-1010.

[9] Abraha MG, Savage MJ. Comparison of estimates of daily solar radiation from air temperature range for application in crop simulations. Agricultural and Forest Meteorology 2008; 148(3): 401-416.

[10] Chineke TC. Equations for estimating global solar radiation in data sparse regions. Renewable Energy 2008; 33(4): 827-831.

[11] Duffie JA,Beckman WA, Solar engineering of thermal processes [M]. New York:Wiley, 1991.

[12] Frohlich C, London J, editors, "Revised instruction manual on radiation instruments and measurements," World climate research program, Publication Series No.7, WMO/TD-No.149. World Meteorological Organisation:Geneva, 1986, 140 pp. 